\title{
Modelling of Direct Connection of Heat Consumers to District Heating with Ejectors
}

\author{
Xhevat Berisha", Drilon Meha\# \\ ${ }^{\#}$ Faculty of Mechanical Engineering, University of Pristina “Hasan Prishtina," Str. Sunny Hill n.n., Pristina, 10000, Kosovo \\ E-mail: xhevatberisha@uni-pr.edu,drilon.meha@uni-pr.edu
}

\begin{abstract}
Energy requirements by thermal consumers are continually increasing as a result of the growing standards of living conditions. Thus, to meet the demands with thermal energy, and to use thermal energy more efficiently it was seen a reason to do the following analysis with the purpose of finding the influence of the most efficient distribution of thermal energy for the district heating of Pristina city. The current paper describes the operation of the ejectors applied for direct connection by mixing the hot water from district heating network with the cold water used for heating systems. This paper is, based on the simulations analysis of the water supply temperatures at the secondary network $t_{\mathrm{ws} 2}$, which are, derived from the modelling of ejector compared with water supply temperatures, which uses the enterprise of "Termokos" with heat exchangers. Furthermore, the results gained by CFD modelling have shown considerable thermal energy savings potentials and will be useful for the maintained engineer of district heating of Pristina City to make a suitable prediction of the design specifications to use thermal energy more efficiently.
\end{abstract}

Keywords - ejector; heat exchanger; thermal substation; district heating; temperature distribution; CFD modelling; efficiency

\section{INTRODUCTION}

Ejectors are mechanical devices that use the effect of a converging-diverging nozzle, suction chamber, and a diffuser, to convert pressure energy of the actuating fluid, which may be a gas, vapor or liquid, water into kinetic energy.

Ejectors are used in various fields of the industry since they are used, with multiple working fluids, i.e., in the delivering tube, the fluid can be liquid, while in the suction tube the fluid can be liquid, gas or multiphase mixture. Further, ejectors find extensive applications when the working fluids are gas-gas. As this study deals with liquidliquid ejector, also known as a jet pump; the following sections address the effects of using ejectors in district heating.

The application of ejectors in thermal substation helps in using the energy sustainably. The ejectors are static devices, and this is the case that they have more extended longevity than other tools applied to the same destination.

A detailed analysis of the main pipeline is conducted to analyse the contours of pressure, velocity, and temperature. The results gained from calculations have shown that all heat consumers analysed can apply direct connection in the district heating - after the stated conditions in the reference are satisfied [1], [2].
The following analysis of modelling ejector is done to address the issues of contours of velocity, pressure, and temperature through ejector and their application to district heating of Pristina. Jiankai Dong [3] established the calculation of the water stability in ejector including some factors that might influence the stability of the water ejector, - the system form, and the design outdoor air temperature, the design supply /mixing/ discharge water temperatures, the number of the floors, and the heat transfer coefficient were also analysed.

The application of ejector in the centralized heating system had also drawn some attention; in primary and secondary network direct connection system by Ren and Zhang [4] and studies for designing an ejector pump for a hydraulic system for discharging water and emptying tanks by Sipridonow [5]. Similar reviews of water ejector by using computers tools for a simulation like ANSYS were performed by Nedelcut et al. [6]. Another paper which studied various simulation parameters for a modified ejector used in automotive industry was conducted with three design of motive nozzle: standard, with additional circumferential holes and with a set of circumferential holes on motive nozzle by Lisowski and Momeni [7]. Moreover, a reviewer of the efficiency of ejectors for various systems was performed by Liu [8].

Computational fluid dynamic CFD analysis and design optimization of jet pumps were done by Fan et al. [9] and 1- 
D mathematical modelling and CFD investigation on supersonic steam ejector in MED-TVC by Hanafi et al. [10]. The usage of ejectors, such as jet pumps, was studied by Liu et al. [11], and Green [12]. Hydrodynamic and thermal analysis of district heating was, performed by Ren [4], Meha [13] and Berisha [14] with a focus on the district heating of Pristina.

\section{MATERIAL AND METHOD}

The usage of district heating for a particular area is one of the critical parameters for improving thermal efficiency. District heating plants using pipe network for distributing heat generated in a centralized location for residential and commercial heating requirements can provide higher efficiencies than localized boilers.

Also, the way of how thermal consumers are connected to the district heating has an extraordinary effect on thermal energy savings.

In general, there are two forms of connecting thermal consumers in district heating networks through thermal substations: heat exchangers or ejectors.

In heat exchangers the heat flux is exchanged indirectly, for example, fluids transfer heat with each other, but they do not mix them. The opposite occurs in the ejector devices when these streams of flowing fluids are mixed with each other. This method is also known as the direct connection of heat consumers in district heating. It is considered more favourable than indirect way, with heat exchangers, due to the higher utilization of available thermal energy.

Moreover, ejectors are simple devices: they have a simple construction, require less maintenance and capital cost, and offer higher sustainability compared to other devices. Following the facts as mentioned above, the analysis of pressure, temperature, and velocity contours are performed in this paper to conclude if it is worth installing such a device.

The method of the connection depends on many factors, such as the height of buildings. This paper analyses a part of the main pipeline of district heating for which connections with ejectors can be applied.

The ejector is a static device that is composed of nozzle, delivery and suction tube, mixing chamber and a diffuser. To make ejector modelling possible, firstly the parameters at the entrance and exit of this device should be defined. The entrance parameters like pressure, velocity, and water flow are dependent on the main pipeline characteristics (see section A).

After this analysis for a particular heat consumer was done, there were assumed presented parameters in section B. This made possible to analyse the contours of pressure, temperature, and velocity; which are the basic parameters that determine meeting or not the conditions of heat consumers for application of such ejectors.

Fig. 1 shows a heat exchanger and an ejector. As can be seen from the right scheme, the return temperatures in the primary and secondary network are the same, which is not the case, appeared to heat exchangers. These means that water supply temperature in secondary side respectively $t_{w s 2}$ will be higher than there is used a heat exchanger. To predict this increase in temperature at the exit of the ejector, we did a flow simulation with Solid Work 2014 software, to see how will change the supply water temperature in the secondary side will increase thermal energy saving, in contrast, there is used a heat exchanger for the same parameters. Within those simulations are also addressed the effects of the outside of air temperatures, which use Termokos, such as water supply temperature in demand side, contours of velocity, pressure, and temperature through the ejector, etc.

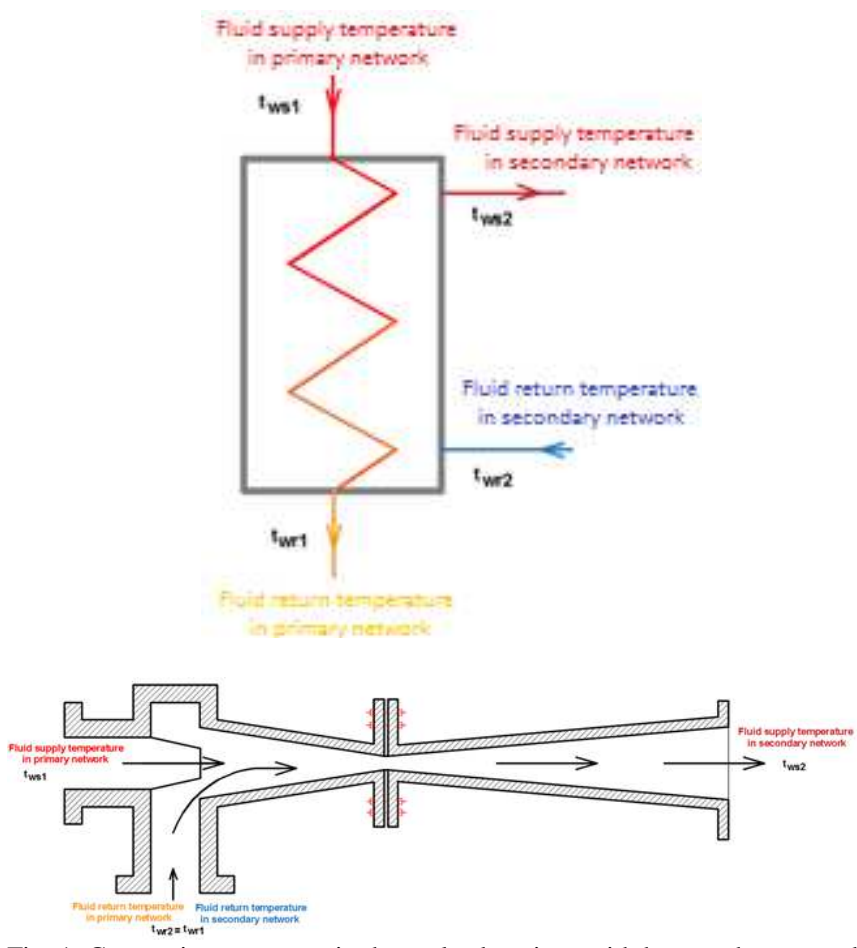

Fig. 1 Connections manners in thermal substations with heat exchanger and ejector

To address above mentioned issues CFD analysis of ejector is done with Solid Work Flow simulation, which was extremely useful for determining the distribution of velocity, pressure, and temperature through the ejector. The result gained from the CFD flow simulation analysis can be used from designers to assign the right size of ejectors and to choose, whether it is worth to apply such a device to a heat exchanger. In Fig. 2, the geometric characteristics of modelling ejector are given.

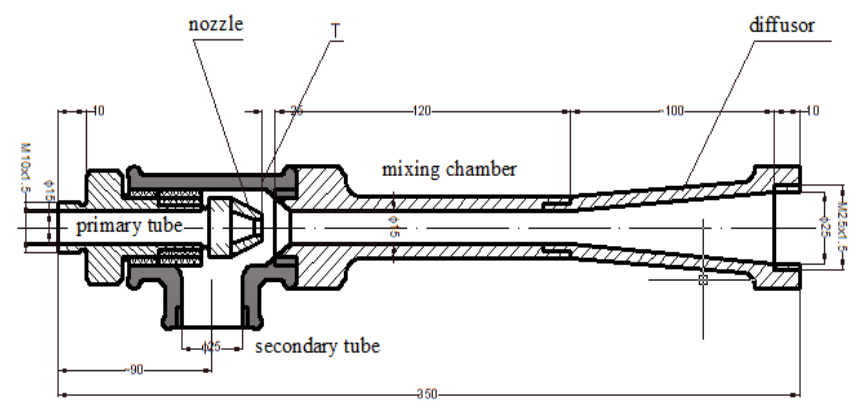

Fig. 2 The geometry of modelling ejector

\section{A. Model of the Main Pipeline}

TermoKos is the main supplier of thermal energy in Pristina, through its two pipelines. The first pipeline leaves the TermoKos with a nominal diameter of $600 \mathrm{~mm}$, while 
the other with $500 \mathrm{~mm}$. The first pipeline supplies with thermal energy the neighbourhoods of Dardania and Qender. The second pipeline supplies the neighbourhoods of Ulpiana, Sunny Hill, and Clinical Centre of Kosovo [13]. The main pipeline analysed in this paper is described with sectors presented in Table 1.

TABLE I

GEOMETRY OF PIPELINE FROM TERMOKOS - SUNNY HILL

\begin{tabular}{|l|c|c|c|c|}
\hline Sector & H [m] & $\mathbf{L}[\mathbf{m}]$ & $\mathbf{D}[\mathbf{m m}]$ & Elbow [-] \\
\hline T-P01-P02 & 583.0 & 50.0 & 500.0 & 4 \\
\hline $\begin{array}{l}\text { P03-P04-P05- } \\
\text { P06 }\end{array}$ & 586.0 & 200.0 & 500.0 & 2 \\
\hline P07-P08 & 590.0 & 100.0 & 457.2 & 1 \\
\hline P08-P09 & 591.0 & 25.0 & 457.2 & - \\
\hline P09-P10 & 592.0 & 6.2 & 457.2 & - \\
\hline P10-P36 & 596.0 & 135.0 & 406.0 & - \\
\hline P36-P37 & 593.0 & 69.0 & 406.0 & 1 \\
\hline P37-P38 & 596.0 & 112.0 & 406.0 & - \\
\hline P38-P39 & 600.0 & 130.0 & 406.0 & 1 \\
\hline P39-P40 & 606.0 & 264.5 & 273.0 & - \\
\hline P40-P41 & 611.0 & 90.0 & 273.0 & - \\
\hline P42-P43 & 608.0 & 50.0 & 114.3 & - \\
\hline P43-P44 & 609.0 & 100.0 & 114.3 & - \\
\hline P44-P45 & 610.0 & 150.0 & 114.3 & - \\
\hline
\end{tabular}

Table 1 presents the inputs taken from TermoKos. The first column shows the sectors of the main pipeline from TermoKos to Sunny Hill. The second column gives the height position from the sea level, while the third column displays the length of the sectors. Moreover, the fourth column presents the diameter of the segments, and the last one the number of elbows in specific sections of the main pipeline [13].

\section{B. Governing Differential Equations for the Pipe Network}

The basis for the computation of one-dimensional flow in pressure pipelines is a differential equation system consisting of a momentum, continuity and a heat flow equation. The flow equations can be written in the following form using the variables pressure $\mathrm{p}$ and discharge $\mathrm{Q}$ [16]:

$$
\begin{aligned}
& \frac{\partial Q}{\partial t}+\frac{Q}{A} \frac{\partial Q}{\partial x}-\frac{Q}{A} \frac{\partial A}{\partial p} \frac{\partial p}{\partial t}-\frac{Q^{2}}{A^{2}} \frac{\partial A}{\partial x}+ \\
& +g A \frac{\partial p}{\partial x}+g A S_{F}-a_{x} A=0 \\
& \frac{1}{\rho a^{2}}\left(A \frac{\partial p}{\partial t}+Q \frac{\partial p}{\partial x}\right)+\frac{\partial Q}{\partial x}-\frac{Q}{A} \frac{\partial A}{\partial x}=0
\end{aligned}
$$

Where $\mathrm{g}=$ acceleration of gravity; $\mathrm{z}=$ coordinate of height; $\mathrm{SF}=$ friction slope $\rho=$ density; $\mathrm{a}=$ velocity of the pressure wave; $\mathrm{x}=$ coordinate axis along the pipe; $\mathrm{t}=$ time; $\mathrm{a}_{\mathrm{x}}=$ additional acceleration in $\mathrm{x}$-direction.

The friction slope $S_{F}$ can be determined according to Darcy-Weisbach by the following expression using the friction coefficient $\lambda_{F}[16]$ :

$$
S_{F}=\frac{\lambda_{F}}{d} \frac{Q|Q|}{A^{2} 2 g}
$$

For the calculation of the friction coefficient $\lambda_{F}$ a formulation based on ZANKE is implemented [16]:

$$
\lambda_{F}=(1-\alpha) \frac{64}{R_{e}}+\alpha\left(-2 \log \left(2.7 \frac{\left(\log \left(R_{e}\right)\right)^{1.2}}{R_{e}}+\frac{k_{s} / d}{3.71}\right)\right)^{-2}
$$

Where $\alpha=$ weighing function; $\mathrm{R}_{\mathrm{e}}=$ Reynolds number; $\mathrm{k}_{\mathrm{s}}=$ equivalent sand roughness; $\mathrm{d}=$ pipe diameter.

Advantages of equation (5) are the explicit calculation of the friction coefficient as well as to have a continuously differentiable function for both laminar and turbulent flow conditions.

Based on the consumer demand for thermal energy, as per the thermal network in Table 1 and governing differential equations for the pipe network, in this study we will calculate the quantity, velocity of heated water, and the Reynolds number for the main network.

As shown in Fig. 3, the mass flow of water $311 \mathrm{~kg} / \mathrm{s}$ enters in the main pipeline and is spread in other sectors with the presented values of mass flow meeting the demand of heat consumers for thermal energy [15]. The diagram of water velocity for the actual pipeline was developed using the same method. Having determined the needed mass flow from the thermal consumer and the diameters of the sectors, the construction of water velocity diagram was made possible.

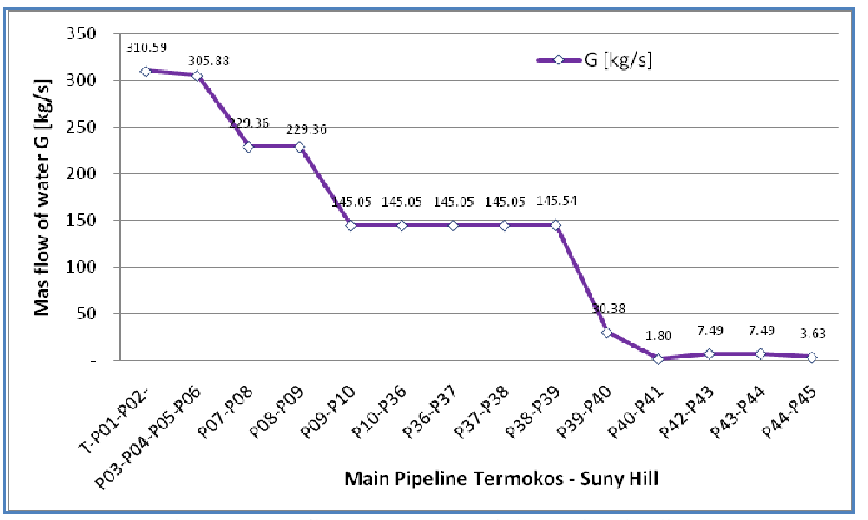

Fig. 3 Mass flow vs sectors of the main pipeline

As can be seen from Fig. 4 the velocity of the water passing through this pipeline is under permission values. The diagram shows that TermoKos is considering increasing the supply of thermal energy to other neighbourhoods by using the actual pipeline network. TermoKos must prepare a more significant amount of mass flow of water if it wants to increase the supply of thermal energy. By doing so, we will be able to identify if the water velocity through sectors is under or above permitted levels (comparing actual diagram of Fig. 4 with a reconstructed diagram).

Fig. 5 Presents calculation of the Reynolds number in sectors of the analysed pipeline [2], [16]. The geometrical characteristics of pipes are taken from the producer LOGSTOR [17], for which the inner ruthlessness of pipes was $0.05 \mathrm{~mm}$. As shown, the flow regime in these sectors is turbulent. The high value of Reynolds number increases the heat transfer with convection from inner tube by causing a 
significant increase in heat losses. Therefore, the insulation of pipelines and optimization of district heating should be taken into consideration when designing the district heating.

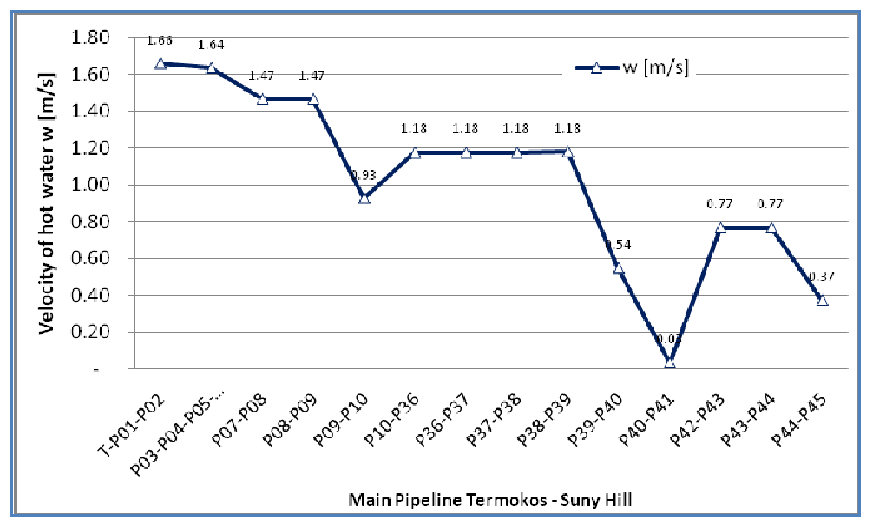

Fig. 4 Water velocity vs sectors of the main pipeline

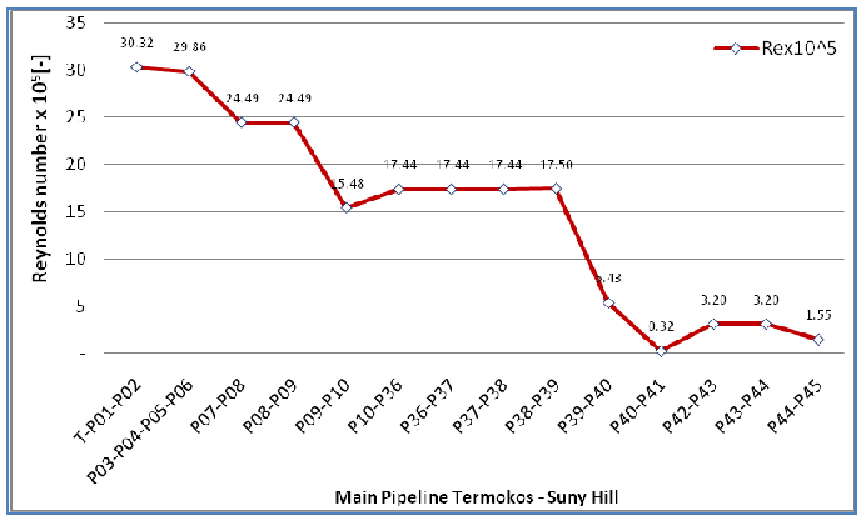

Fig. 5 Reynolds number vs sectors of the main pipeline

\section{Mathematical model of the ejector}

A mathematical model of the ejector consists of mass, momentum, and energy conservation equations. When equations are applied in boundary volume VC bounded by control surface SC, the mass equation, in general, can be written as [16]:

$$
\frac{\partial}{\partial t} \int_{V C} \rho \cdot d V+\int_{S C} \rho \cdot v \cdot d S=0
$$

Where:

$\rho$ - fluid density,

$v$ - fluid velocity,

$t$ - time.

The momentum conservation in general form is as follows [16]

$$
\begin{aligned}
& \frac{\partial}{\partial t} \int_{V C} \rho \cdot v \cdot d V+\int_{S C} \rho \cdot v \cdot(v \cdot d S)= \\
& =\int_{S C} p \cdot d S+\int_{S C} \tau \cdot d S+\int_{V C} \rho \cdot f_{e} \cdot d V
\end{aligned}
$$

Where:

$\tau$ - shear stress tensor,

$f_{e}$ - vector of external forces,

$p$ - pressure. [16]:

$$
\begin{aligned}
& \frac{\partial}{\partial t} \int_{V C} \rho \cdot E \cdot d V+\int_{S C}(\rho \cdot v \cdot H-k \cdot \nabla T-\tau \cdot v) \cdot d S= \\
& =\int_{V C}\left(\rho \cdot f_{e} \cdot v+q_{H} \cdot d S\right.
\end{aligned}
$$

Where:

$$
\begin{array}{ll}
E=e+v^{2} / 2 & \text { - total energy. } \\
e & \text { - internal energy, } \\
H=E+p / \rho & \text { - enthalpy, } \\
W_{f}=f_{e} \cdot v & \text { - work of external forces,. } \\
q_{H} & \text { - heat released by chemical; reactions, } \\
k & \text { - conductivity coefficient, } \\
T & \text { - absolute temperature. }
\end{array}
$$

D. Analysis of Contours of Velocity, Pressure, and Temperature by Solid Works 2014

Computational Fluid Dynamics, CFD, is a branch of fluid mechanics, which is defined as the set of methodologies that enable the computer to provide us with a numerical simulation of fluid flows [16]. CFD analysis of ejector can be used for distribution of velocity, pressure, and temperature through ejector. The result gained from CFD will be useful for designers to dimension the right size of ejectors. Computer simulation tools developed last year, like CFD - Computational Fluid Dynamics provide much deeper possibilities in modelling fluid flow and are also found in the modelling of jet pumps [6].

Phenomena that occur in the ejector are complex. Hence, even the usage of the models and equations presented above may not give exact results (with assumed simplifications applied in the modelled ejector). Therefore, in this work, CFD methods were used to simulate fluid flow in the defined ejector model (EM). CFD analysis was carried out with the following assumptions [2], [13], [16]:

- Flow is incompressible and homogenous

- There is no heat transfer between fluids and environment,

- Roughness of walls was neglected, and

- The analysis was conducted under steady state conditions.

It was assumed the following fluid properties:

- Water temperature in the primary network $t_{p}=90^{\circ} \mathrm{C}$

- Water pressure in the primary network $p_{p}=2.01325$ bar

- Water pressure in the primary network $p_{\mathrm{s}}=1.01325 \mathrm{bar}$

- Water mixed mass flow $\mathrm{m}=0.6 \mathrm{~kg} / \mathrm{s}$

- Density of water $\rho=1000 \mathrm{~kg} / \mathrm{m}^{3}$

- Viscosity of water $\mu=1.003 \mathrm{e}-3 \mathrm{~Pa} \cdot \mathrm{s}$

- The fluid flow is turbulent; a Reynolds Stress model was used.

The CFD model of the ejector is shown in Fig. 2.

\section{RESULTS AND DISCUSSION}

Drawing of the ejector in Solid Works 2014 prepared for flow simulation is given in Fig. 6 In Solid Works should also be defined the boundary conditions such as pressure, flow mass and temperature in the primary tube, secondary tube and at the exit of the diffuser. The data values are shown in the following figures. 


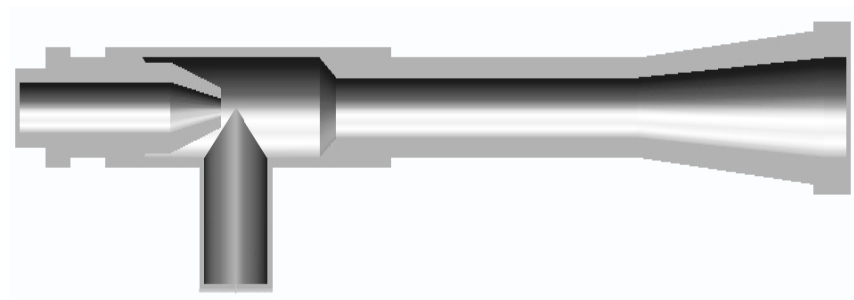

Fig. 6 Geometrical presentation of water ejector

Fig. 7 shows the effect of the outside air temperature at the water supply temperature, which is prepared at the enterprise of "Termokos" and then is sent to the thermal consumers of the city of Pristina for filling the demands with thermal energy. Fig. 7 shows that with the rise of the outdoor air temperature, the thermal energy produced by "Termokos" is reduced almost linearly. This diagram is applied by "Termokos" to prepare water with temperatures needed by thermal consumers.

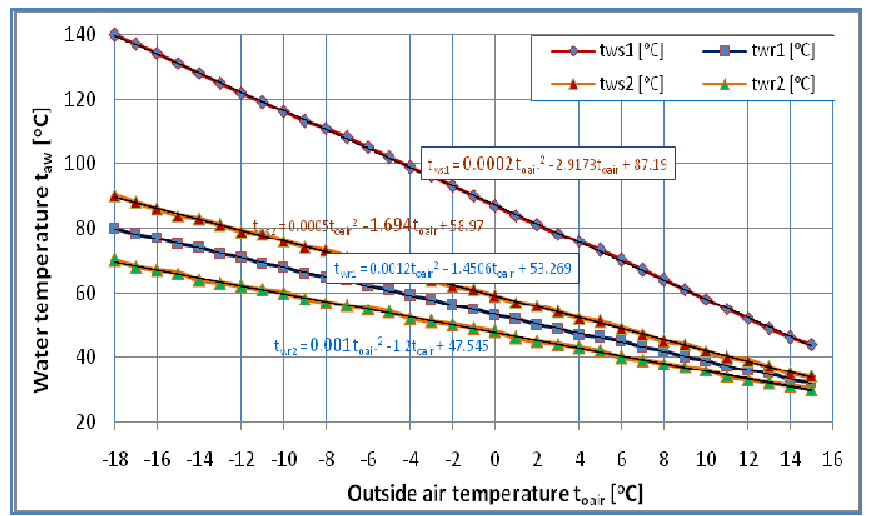

Fig. 7 Water temperature in the primary and secondary network as a function of outside air temperatures [14]

For various intervals of outside air temperature, $\Delta \mathrm{t}=5^{\circ} \mathrm{C}$, in the following figures are presented the results of modelling ejectors such as the contours of water velocity, pressure, and temperature. Water supply temperature at the secondary network $\mathrm{t}_{\mathrm{ws} 2}$ is not known, then by applying solid work simulations, we can predict it. By doing so, we will use thermal energy in a more efficient way. Water flows from the primary network installation (district heating), with a range of temperature differences for $5{ }^{\circ} \mathrm{C}$ depending on outside air temperature (see Fig. 7) for primary and secondary tube has been analysed.

Other, parameters such as absolute pressure in primary tube 2.01325 bar [13], and static pressure in secondary tube 1.01325 bar [1], have remained constant for the reasons of regulating the temperature of water mixed with the mass flow at the outlet of diffusor of $0.6 \mathrm{~kg} / \mathrm{s}=$ const, which is sent to the heat consumer in order to meet the demands with thermal energy. The above-mentioned parameters have remained unchanged for various modelling of outside air temperatures.

From Fig. 8, it can be seen the water velocity distribution through parts of the ejector, depending on the outside air temperature $-18{ }^{\circ} \mathrm{C},-10{ }^{\circ} \mathrm{C}, 0{ }^{\circ} \mathrm{C}, 5{ }^{\circ} \mathrm{C}, 10{ }^{\circ} \mathrm{C}, 15{ }^{\circ} \mathrm{C}$. As can be seen from the same figure the effect of outside air temperature in water velocity streams through the ejector is pretty small. The highest value of water velocity at the exit of nozzle $13.4 \mathrm{~m} / \mathrm{s}$ is taken when the air temperature was $0^{\circ} \mathrm{C}$. In this case, the temperature of water in the primary tube was $361.05 \mathrm{~K}$, and the temperature in the secondary tube was $327.65 \mathrm{~K}$.
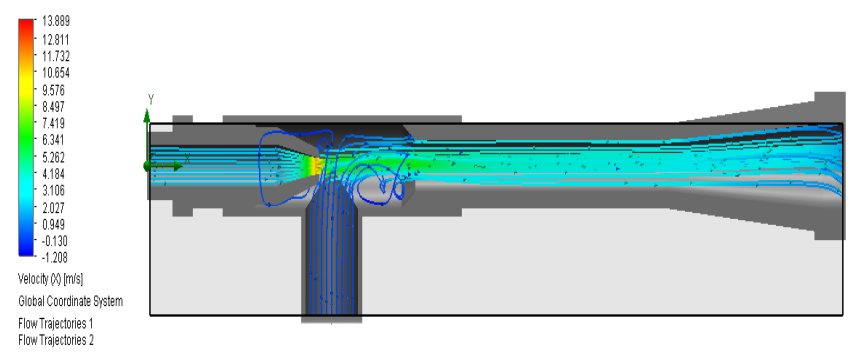

(a)

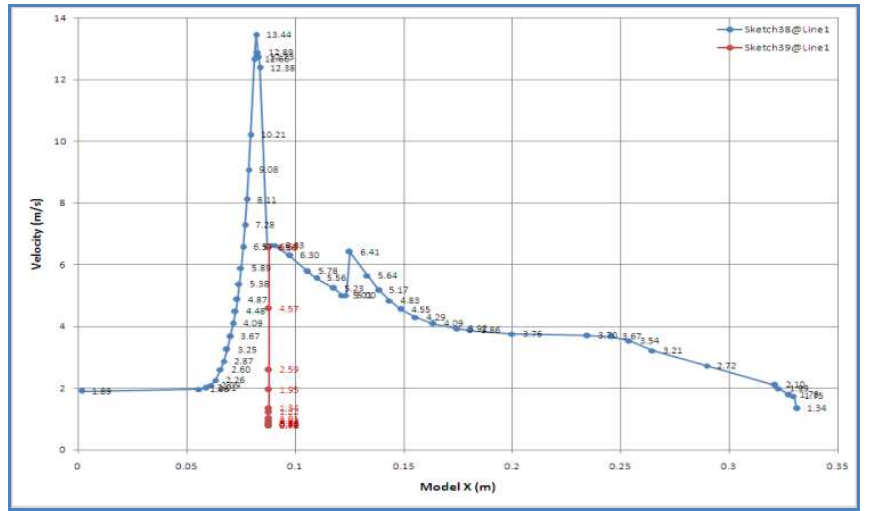

(b)

Sketch 38@Line 1: The centre line through upper part of ejector (primary tube, nozzle, mixing chamber, diffuser);

Sketch39@Line 1: The centre line through the second tube of the

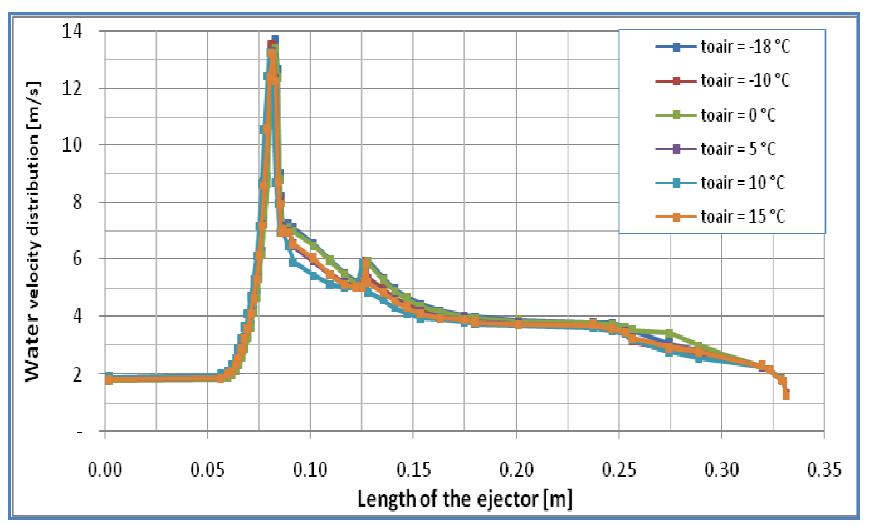

(c)

Fig. 8 (a) CFD Contours of velocity through ejector (b) ) CFD Velocity distribution through ejector (c) Contours of water velocity through ejector

Usually, the water flow velocity in the secondary network (heat consumer) should be about $1.2 \div 3.0 \mathrm{~m} / \mathrm{s}$. In Fig. 8 it is seen that the water velocity varies from $2.0 \mathrm{~m} / \mathrm{s}$ to the primary tube and reaches the maximum velocity at the exit of the nozzle $13.5 \mathrm{~m} / \mathrm{s}$. After leaving the nozzle, the water velocity drops sharply. The very high speed of the outlet stream allows the entraining of the water from the secondary network at a velocity of $6.2 \mathrm{~m} / \mathrm{s}$. The water mixed with the flow due to the expansion of the section in which it flows decreases up to $5 \mathrm{~m} / \mathrm{s}$ at the entrance of the mixing chamber. Due to the narrow section of this part, a drastic increase of velocity of up to $6.0 \mathrm{~m} / \mathrm{s}$ is observed. In the mixing chamber, the speed is constant, while during the flow through the diffuser, the velocity continues to decrease to $1.2 \mathrm{~m} / \mathrm{s}$, where it is sent to the thermal consumer. These values do not change considerably with the change of outside air temperatures. 


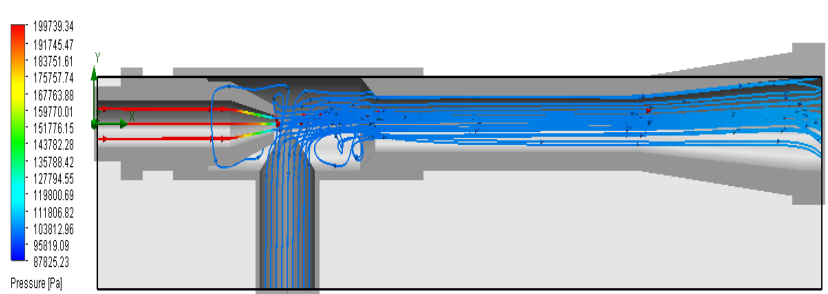

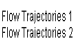

(a)

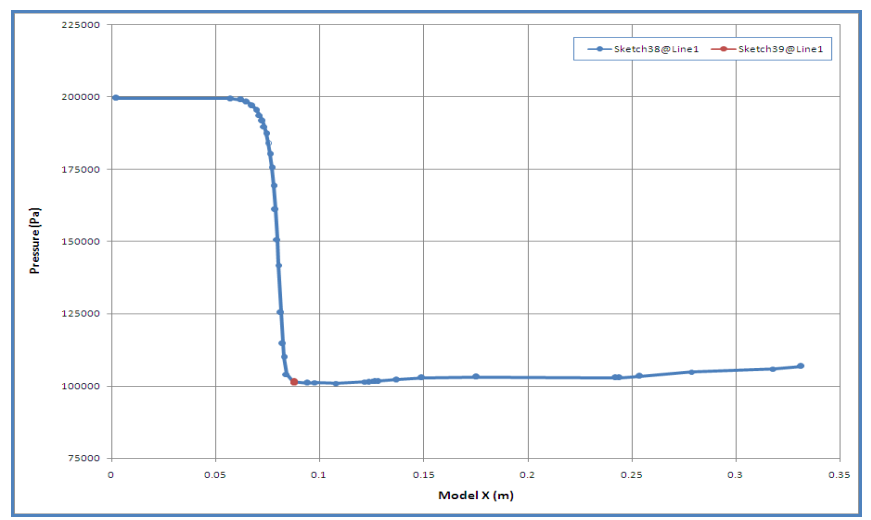

(b)

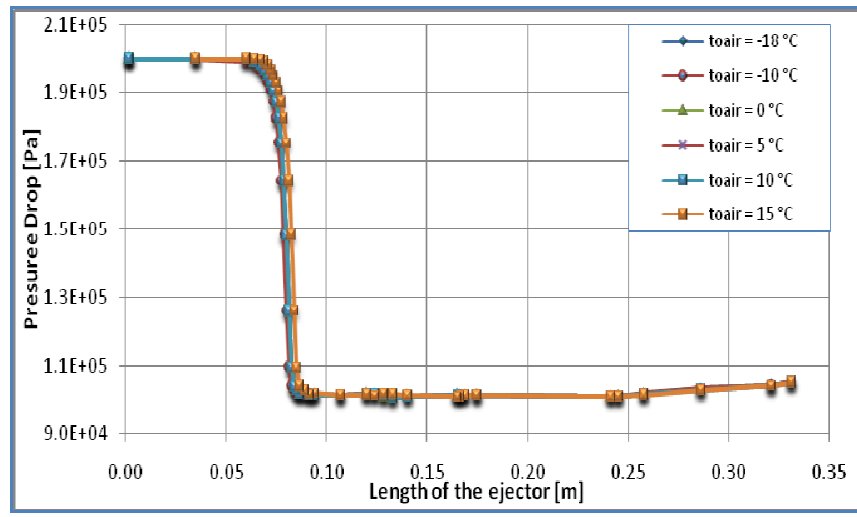

(c)

Fig. 9. (a) CFD Contours of pressure through ejector (b) CFD Pressure distribution through ejector (c) Contours of pressure distribution through parts of the ejector

From the above-presented analysis, we can conclude that the outside air temperature does not have any visible effect on pressure drop characteristics through ejector.

In Fig. 10 is presented the water temperature distribution through ejector for various outside air temperatures. As can be seen from Fig. 10 for a higher temperature of water in primary tube respectively for the smallest values of outside air temperatures, the effect of water supply temperature at the exit of the ejector is almost invisible. The last values of temperatures presented on the right side show the water supply temperatures in the secondary network depending on outside air temperature when there are applied ejectors.

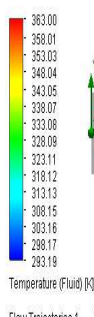

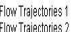

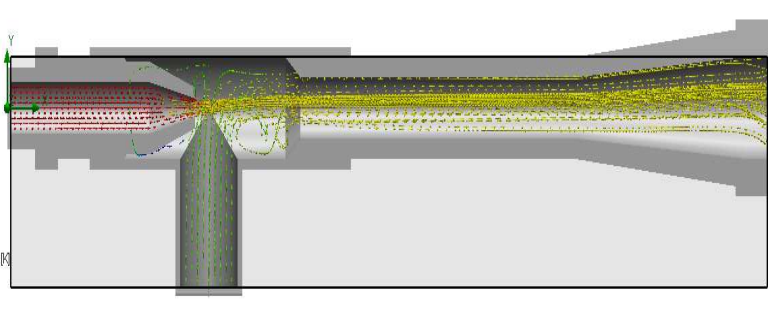

(a)

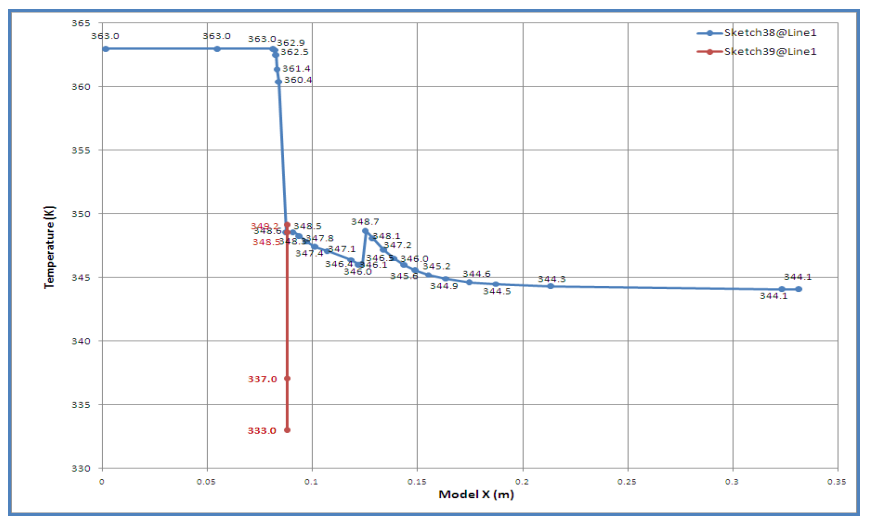

(b)

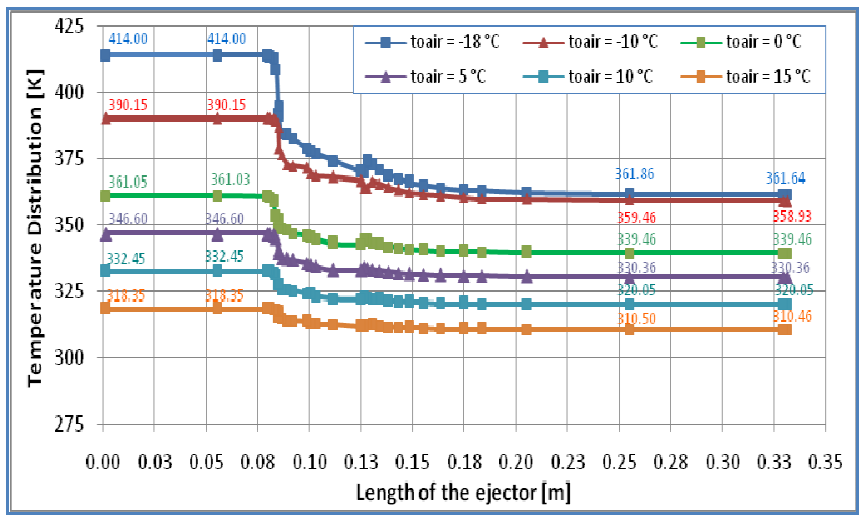

Fig. 10. (a) CFD Contours of temperature through ejector (b) CFD Temperature distribution through parts of ejector (c) The temperature of water distribution through parts of the ejector

Water supply temperatures at the secondary network when there are used ejectors are higher than water supply temperatures, which are applied with heat exchangers by the enterprise of Termokos. This means that for the same heat demands by the thermal consumer when there are applied ejectors the mass flow of hot water supply is lower. In Fig. 11 with the red line is presented the water supply temperature in the secondary network when in thermal substations are installed heat exchangers, while with blue line is presented the water supply temperature in the secondary network when in thermal substations are installed, ejectors. Equations depending on outside air temperature that best describes the water supply temperatures in the secondary network for above-mentioned connections are given in the same figure. 


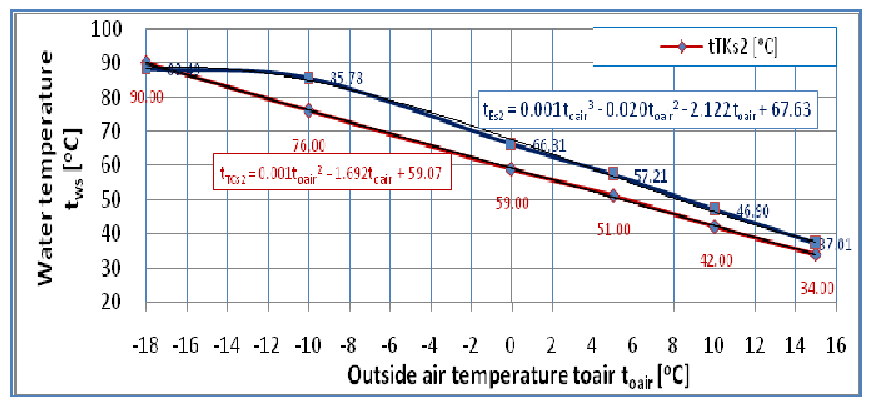

Fig. 11 Water supply temperature in the secondary network as a function of outside air temperature when there are used heat exchangers $t_{\mathrm{TCs} 2}$ and ejectors $t_{\mathrm{Es} 20}$

In Fig. 12 is shown the percentage of thermal energy savings achieved. This figure shows that when the outside air temperature is equal to the outside air design temperature $-18{ }^{\circ} \mathrm{C}$, the ejector application is not suitable for usage compared with a heat exchanger. When the outside air temperatures vary from $-10{ }^{\circ} \mathrm{C}$ to $10{ }^{\circ} \mathrm{C}$, the thermal energy savings from the direct connection modes reach a percentage over $10 \%$. Since the analysis done by Krasniqi [1] has shown that the outside air temperature for the heating season is approximately $4.6^{\circ} \mathrm{C}$ for the city of Pristina, the application of ejectors for these conditions are extremely desirable.

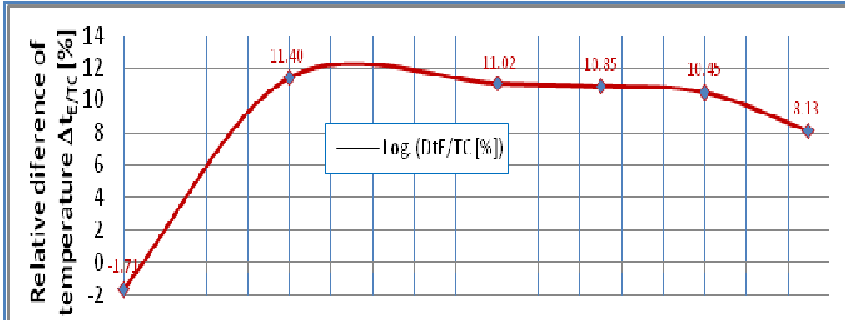

$\begin{array}{lllllllllllllllllll}-18 & -16 & -14 & -12 & -10 & -8 & -6 & -4 & -2 & 0 & 2 & 4 & 6 & 8 & 10 & 12 & 14 & 16\end{array}$ Outside air temperature toair $\left[{ }^{\circ} \mathrm{C}\right]$

Fig. 12 Relative compressions of energy saving derived from water supply temperatures in the secondary network depending on outside air temperature when there are used heat exchangers $\mathrm{t}_{\mathrm{TC} 2}$ and ejectors $\mathrm{t}_{\mathrm{Es} 20}$

Further, when the outside air temperature is between intervals of -10 to $0^{\circ} \mathrm{C}$, the effect of thermal energy saving has reached its maximum. This means as much higher the difference between $t_{\mathrm{Es} 2}$ and $\mathrm{t}_{\mathrm{TSs} 2}$ to be; the higher thermal energy savings are achieved. For outside air temperature $18^{\circ} \mathrm{C}$ this difference is invisible, while when $\mathrm{t}_{\text {oair }}=15^{\circ} \mathrm{C}$ there is shown a considerable thermal energy saving potential.

In the axis of Fig. 13 are given the sectors of the main pipeline from the enterprise of "Termokos" to the neighbourhood of Sunny Hill in units [m], while in the ordinate is given the piezometric water pressure in $[\mathrm{m}]$. For the construction of the above-presented diagram refer to the references [13], [14].

Another key component for applications of ejectors is the disposable pressure between primary and return tube, which should be above $15 \mathrm{~m}$ to make the possible normal operation of the ejector. From the figures, it can be seen that for the pipeline in the city of Pristina, for which the piezometric diagram has been constructed, it is possible to realize the direct connection of heat consumer with ejectors, since this disposable pressure is more than $15 \mathrm{~m}$.

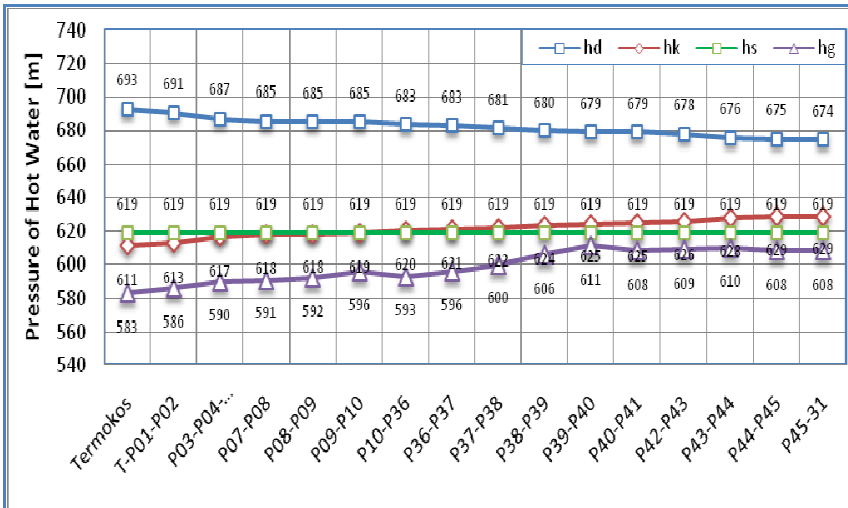

Fig. 13 Piezometric diagram created for the main pipeline of Pristina city, which supply with thermal energy neighbourhood of Sunny Hill and Hospitals [13]

\section{CONCLUSION}

The effect of various outside air temperatures has a visible impact to water temperatures in the primary and secondary tube of the ejector compared with other parameters such as the distribution of contours of pressure, and water velocity through ejector. Also, the possibility of applying ejector equipment to the district heating of Pristina city against heat exchangers enables using of thermal energy in a more efficient and systematic way. From the above analysis is concluded that when the outside air temperature is between intervals of -10 to $0^{\circ} \mathrm{C}$, the effect of thermal energy saving reaches it's maximum. This means as much higher the difference between $t_{\mathrm{Es} 2}$ and $\mathrm{t}_{\mathrm{TSs} 2}$ to be the higher thermal energy savings are achieved. For outside air temperature $18{ }^{\circ} \mathrm{C}$ this difference is invisible, while when $\mathrm{t}_{\text {oair }}=15^{\circ} \mathrm{C}$ there is shown a considerable energy saving. Since the temperature of heating season for Pristina city is $4.6{ }^{\circ} \mathrm{C}$; the ejector has shown a great potential for reducing energy demands compared with heat exchangers in the demand side. Further, the ejector devices to be considered for applications in thermal substations should also fulfil some other conditions related to the construction side of the building [1].

\section{REFERENCES}

[1] Krasniqi F., "Chapter 6. Thermal Networks," in Cogeneration and Thermal Networks, Special Ed. CXIII, Pristina, Kosovo, Kosovo Academy of Sciences and Arts, 2010, pp. 209-244.

[2] Cunningham, R.G. "Chapter 4, Jet Pumps, Section 4.1 Jet Pump Theory, and 4.2 Jet Pump Applications, " in Pump Handbook, $3^{\text {rd }}$ ed., McGraw-Hill, 2001, pp. 641-687. http://www.petrodanesh.ir/Virtual\%20Education/Mechanics/Pump/P ump\%20Handbook-McGraw-HILL.pdf

[3] Dong, J., Li, L., Jiang, Y., Wang, P., "The Stability of Water Ejector," Procedia Eng., vol. 121, pp. 1252-1258, 2015. https://doi.org/10.1016/j.proeng.2015.09.153.

[4] Ren, W.Y., Zhang, X., "Application of Water Jet Pump in Heating System," Energy and Energy Conservation, pp. 62-64, 2011. http://en.cnki.com.cn/Article_en/cjfdtotal-sxj1201101030.htm

[5] Sipridonow, E.K., "Designing an Ejector Pump for a Hydraulic System for Discharging Water and Emptying Tanks," Chem. and Petro. Eng., vol. 41, no. 1-2, pp. 66-74. doi:10.1007/s10556-0050062-1.

[6] Nedelcut, F., Iacob, N., Cuciuc, C. "ANSYS Flowizard used to optimize a water ejector," Journal of Ind. Design and Eng. Graphics, vol. 7, no. 2, pp. 19-22, 2012. https://www.researchgate.net/ publication/308349408.

[7] Lisowski, E., Momeni, H., "CFD Modeling of a Jet Pump With Circumferential Nozzles for Large Flow Rates," Archives of Foundry Eng., vol. 10, no. 3, pp. 69-72., 2010. http://www.afe.polsl.pl/ 
index.php/en/2513/cfd-modelling-of-a-jet-pump-withcircumferential-nozzles-for-large-flow-rates.pdf.

[8] Liu, F., "Review on Ejector Efficiencies in Various Ejector Systems," Inter. Refri. and Air Condi., vol. 1533, pp. 1-10. 2014. http://docs.lib.purdue.edu/cgi/viewcontent.cgi?article=2532\&context =iracc.

[9] Fan, J., Eves, J., Thompson, H.M., Toropov, V.V., Kapur, N.,

Copley, D., Mincher, A. "Computational Fluid Dynamic Analysis and Design Optimisation Of Jet Pumps," Computers \& Fluids, vol. 46, pp. 212-217, 2001.

https://doi.org/10.1016/j.compfluid.2010.10.024.

[10] Hanafi, A.S., Mostafa, G.M., Waheed, A., Fathy, A. "1-D Mathematical Modeling and CFD Investigation on Supersonic Steam Ejector in MED-TVC," Energy Procedia, vol. 75, pp. 3239-3252, 2015. doi: 10.1016/j.egypro.2015.07.690.

[11] Liu, X., Deng, H., Ma, W. "Numerical Analysis for Solid-Liquid Two-Phase Flow Field Of Draining-Sand Jet Pump," Proceedings of the 2009 IEEE International Conference on Mechatronics and Automation, 2010. doi.org/10.1109/ICMA.2009.5246584.

[12] Green, A.J. "Jet Pumps and Ejectors," Thermopedia, doi.org/10.1615/Atoz.j.jet_pumps_and_ejectors.

[13] Meha, D. "Hydrodynamic and Thermal Analysis of Thermal Network for the City Of Pristina and Methods of Heat Consumers Connecting to this Network," M.S. thesis, Faculty of Mechanical Eng., University of Pristina, Pristina, Kosovo, 2016.

[14] Berisha, Xh. "Analysis and Synthesis of Working Regimes of Thermal Networks," PhD thesis, Faculty of Mechanical Eng., University of Pristina, Pristina, Kosovo, 2005.

[15] 20Meha, D., Berisha, Xh. "NetCalc -Excel Program," Faculty of Mechanical Eng., University of Pristina, Pristina, Kosovo, 2017.

[16] Streeter, V. L., Wylie, E.B., "Fluid Mechanics, First SI Metric Edition," McGraw-Hill Book Company, 1986.

[17] LOGSTOR, "Pre-insulated pipes for industrial applications," retrieved from https://www.logstor.com/media/1413/industrygeneral_en_p_in.pdf. [Accessed: 22 December 2016]. 